South African Journal of Geomatics, Vol. 3, No. 2, August 2014

\title{
Assessment of the Contribution of WorldView-2 Strategically Positioned Bands in Bracken fern (Pteridium aquilinum (L.) Kuhn) Mapping
}

\author{
Zinhle Ngubane $^{1}$, John Odindi ${ }^{1}$, Onisimo Mutanga ${ }^{1}$, Rob Slotow ${ }^{2}$ \\ ${ }^{1}$ School of Agricultural Earth and Environmental Sciences, University of KwaZulu-Natal, \\ Pietermaritzburg Campus, Pietermaritzburg \\ Odindi@ukzn.ac.za \\ ${ }^{2}$ School of Life Sciences, University of KwaZulu-Natal, Westville Campus, Durban
}

DOI: http://dx.doi.org/10.4314/sajg.v3i2.7

\begin{abstract}
In the eThekwini Metropolitan Area, mitigation of the Bracken fern (Pteridium aquilinum (L.) Kuhn) invasion within the KwaZulu-Natal Sandstone Sourveld (KZNSS) has been identified as a major environmental priority. To facilitate informed interventions, reliable Bracken fern spatial distribution is necessary. Earlier efforts to map the fern using lower spatial and spectral resolution imagery have been unsuccessful. Consequently, this study sought to determine the reliability of the "new generation" World View-2 (WV-2) image characterised by higher spatial and spectral resolution in delineating the fern invaded areas. The eight band WV2 image was atmospherically corrected and spectrally resized as the SPOT-5 wavebands, additional bands and all bands. The classification accuracy was compared to results from the SPOT-5 image. Results showed that classification based on WV-2s additional bands had superior classification accuracy than the rest of the categories. Furthermore, classification based on all the WV-2s bands and the traditional bands perfomed better than the SPOT-5 image in delineating areas covered by the fern. These findings indicate the value of of the "new generation" imagery characterised by higher spatial and spectral resolution in improving the accuracy of the fern invaded landscapes.
\end{abstract}


South African Journal of Geomatics, Vol. 3, No. 2, August 2014

\section{Introduction}

The KwaZulu-Natal Sandstone Sourveld (KZNSS) is one of South Africa's most important grassland ecosystems that provide both social and ecological services to the eThekwini Metropolitan Municipality in KwaZulu-Natal Province, South Africa. In its pristine condition, the grassland is known to be rich in species diversity and provides among other services soil formation, control of erosion, carbon sequestration and recreational opportunities (EThekwiniMunicipality 2012/2013; Msibi 2011). However, in the recent past, the Sourveld has been converted to, among others cultivated land, commercial plantations, alternative vegetation types and urban development. According to Mucina and Rutherford (2006), only $0.2 \%$ of the sourveld is under statutory protection, consequently, long-term sustainability of the vegetation is in doubt.

Encroachment of shrub into the KZNSS landscape has been noted in many parts of the Province (Hudak and Wessman 2001; O'Connor 2005; Wigley et al. 2009). The Bracken fern (Pteridium aquilinum (L.) Kuhn), an aggressive invasive species, has in the recent past been identified as the biggest threat to the KZNSS's remnant patches (Roos et al. 2010; Schneider and Fernando 2010; Msibi 2011). The fern is known to supress resident species, paving way for the emergence of woody plants and forest pioneers (Msibi 2011). Its extensive rooting system enables it to outcompete other species for moisture and nutrients and its typical dense senesced cover impedes germination and growth of other plants. The emerging threats to the KZNSS and its value within eThekwini Municipality necessitates an inventory of the distribution of the fern to facilitate informed intervention.

Traditionally, techniques based on field surveys, aerial photography and review of historical literature among others have been used to determine spatial ecological extents, however, these techniques are often costly, tedious and time consuming (Xie et al. 2008). In the recent past, due to its wide spatio-temporal resolution, availability and lower cost per unit area, remotely sensed data has emerged as a viable tool for land cover mapping (Foody, 2002; Lu et al., 2004; Liu et al. 2004; Kavzoglu and Colkesen 2009; Abd El-Kawy et al. 2011).

To date, land cover mapping studies have comonly used low and medium spatial resolution imagery with limited spectral characteristics. These include SPOT - Cohen and Spies (1992), Kanellopoulos et al. (1992), Landsat - Wulder et al. (2008), Giri et al. (2003), Vogelmann et al. (1998), ASTER - Stefanov and Netzband (2005) French et al. (2008) and MODIS - Stefanov and 
South African Journal of Geomatics, Vol. 3, No. 2, August 2014

Netzband (2005). However, Congalton (1991) and Foody (2002) note that the low spatial and spectral resolutions that characterise such imagery impede reliable delineation of land cover types, particularly in highly heterogeneous landscapes characterised by small land cover types.

Recently, hyperspectral imagery has shown great potential in mapping heterogeneous landscapes (Dalponte et al. 2009; Pignatti et al. 2009; Petropoulos et al. 2012; Petropoulos et al. 2012). However, wide adoption of hyperspectral imagery has been impeded by, among others high cost per unit area, availability and band redundancy (Dalponte et al. 2009, Mutanga et al. 2012).

Despite the potential of remote sensing in the fern mapping, there is paucity in literature on its successful application (Tong et al. 2006). Fuller et al. (1994) for instance mapped a Bracken infested landscape using Landsat TM. Whereas a satisfactory overall classification accuracy between $80-85 \%$ was achieved in other land cover types, the fern classification accuracy was less than 8\%. A number of authors (Birnie and Miller 1986; Miller et al. 1989; Miller et al. 1990; Pakeman et al. 1996 among others) attribute such low classification accuracy to the fragmented patches which are often below the pixel extents of commonly used multispectral images like Landsat and SPOT.

The emergence of "new generation" multispectral sensors such as WorldView-2 offer a valuable trade-off between multi/hyper spectral and low/high spatial resolution imagery (Mutanga et al. 2012). Their higher spatial resolution than traditional low and medium resolution imagery and a higher number of bands at strategic sections of the electromagnetic spectrum offer great potential in land cover mapping (Cho et al. 2012). The WorldView-2 sensor for instance is characterised by four additional spectral bands to those contained in SPOT. The strategic location of these bands within the coastal blue, yellow, red-edge, and NIR2 of the electromagnetic spectrum is valuable for vegetation mapping (Mutanga et al. 2012; Cho et al. 2012).

Based on the aforementioned challenges in mapping the fern using lower spatial and spectral resolution imagery, this study explores the potential of new generation WV-2s additional strategically positioned bands in mapping the fern.

\section{Materials and Methods}

This study was conducted in Giba Gorge, within eThekwini Metropolitan Municipality, KwaZulu-Natal, South Africa (Figure 1). Due to pressure from other land uses on the KZNSS, 
South African Journal of Geomatics, Vol. 3, No. 2, August 2014

private landowners and the Municipality started the Giba Gorge Environmental Precinct cooperative project to manage a common conservation area. However, currently, the biggest threat to the Giba Gorge Environmental Precinct is the displacement of natural habitat by other vegetation forms such as eucalyptus and unplanned fires. The latter has particularly been associated with the fern's invasion (Lindenmayer et al. 2010).

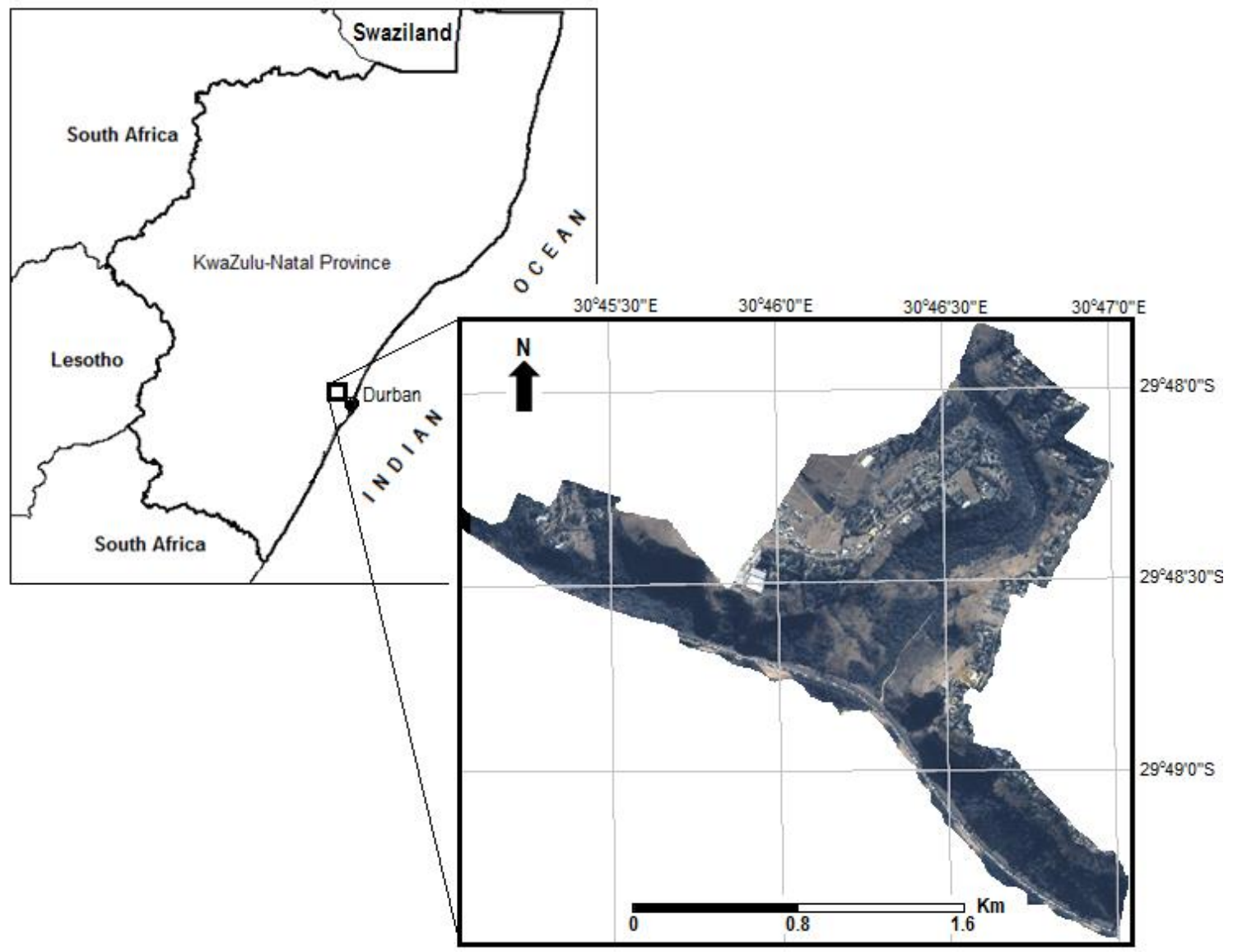

Figure 1: Location of Giba Gorge Environmental Precinct.

Analysis for this study was achieved using an eight band multispectral WV-2 image acquired in July 2012. This time was preferred to maximise separability between the fern and the surrounding vegetation types. This image has a $2 \mathrm{~m}$ spatial resolution and consists of eight spectral bands situated in the coastal blue $(0.4-0.45 \mu \mathrm{m})$, blue $(0.450-0.510 \mu \mathrm{m})$, green $(0.510-0.550$ $\mu \mathrm{m})$, yellow $(0.585-0.625 \mu \mathrm{m})$, red $(0.630-0.690 \mu \mathrm{m})$, red-edge $(0.705-0.745 \mu \mathrm{m})$, NIR1 $(0.770-0.895 \mu \mathrm{m})$ and NIR2 $(0.860-1.40 \mu \mathrm{m})$. For comparison, a SPOT 5 image of the same 
South African Journal of Geomatics, Vol. 3, No. 2, August 2014

area was acquired. The SPOT image has $10 \mathrm{~m}$ spatial resolution with traditional multispectral bands (Blue - 0.450-0.525 $\mu \mathrm{m}$, Green - 0.530 - $0.590 \mu \mathrm{m}$, Red - 0.625 - $0.695 \mu \mathrm{m}$ and NIR $0.760-0.890 \mu \mathrm{m})$. The WV-2 image was atmospherically corrected in Interface Data Language (IDL) ENvironment for Visualising Images (ENVI) 4.7 using the QUAC (Quick Atmospheric Correction) procedure for a World View product. No geometric correction was performed on the WV-2 image as it supplied already corrected by DigitalGlobe. Extensive ground validation data was collected within a week of remotely sensed data acquisition. During the field survey, four major land cover classes (Grass, Forest, Settlement and Water body) were recognised as the most frequently associated with the fern. False colour composites of the WV and SPOT5 images were then used in the field to directly locate and delineate the fern and the other land cover classes. A map of the fern and the common land cover classes was then generated using the field data's GPS readings and aerial photographs. The map was then overlaid on WV2 and SPOT5 images to create regions of interest (ROI) for training and validation. Due to lack of the atmospheric correction procedure for SPOT-5 in ENVI 4.7, the atmospheric correction for the SPOT image was undertaken in IDRISI Andes using the Chavez's COST model (Chavez, 1996). In both the image datasets, a total of 623 reference points was generated, 70\% (436) for training and 30\% (187) for validation.

The WV-2 image was spectrally resized to separate the four traditional bands; blue $(0.450$ $0.510 \mu \mathrm{m})$, green $(0.510-0.550 \mu \mathrm{m})$, red $(0.630-0.690 \mu \mathrm{m})$ and NIR $1(0.770-0.895 \mu \mathrm{m})$ from the additional bands; coastal blue $(0.400-0.450 \mu \mathrm{m})$, yellow $(0.585-0.625 \mu \mathrm{m})$, red-edge $(0.705-0.745 \mu \mathrm{m})$ and NIR2 $(0.860-1.40 \mu \mathrm{m})$. The full and separated WorldView-2 bands and the SPOT images were then used in delineating areas covered by the fern (Table 1).

Table 1: Bands used for analysis - (coastal blue (CB), green $(\mathrm{G})$, yellow $(\mathrm{Y})$, red $(\mathrm{R})$, red-edge (RE), near-infrared 1 and 2 (NIR)).

\begin{tabular}{cccc}
\hline Image & Sensor & Spatial resolution (m) & Spectral bands \\
\hline A & WorldView-2 & 2 & CB,B,G,Y,R,RE,NIR1 \& \\
B & WorldView-2 & 2 & NIR2 \\
C & WorldView-2 & 2 & B,G,R and NIR1 \\
D & SPOT 5 & 10 & CB,Y,RE and NIR2 \\
\hline
\end{tabular}


The maximum likelihood classifier is one of the most commonly used classifiers in remote sensing (Wu and Shao 2002), consequently, it was adopted for this study. This classifier is based on pre-determined spectral characteristics based on Bayesian decision theory and assumes a multivariate Gaussian distribution of each land cover class and distribution. The classifier depends on the statistical characteristics on image training data to generate probability density functions (Atkinson and Lewis 2000). Typically, pixels are allocated to the most likely training data under consideration (Jensen 2005). The maximum likelihood classifier is computationally intensive and depending on the quality of training data, is known to produce reliable classification output (Jensen 2005). The overall, user's and producer's accuracies were calculated and reported for each image.

\section{Results}

The classification based on the four strategically positioned bands (coastal blue, yellow, rededge and NIR2) and the SPOT 5 image produced the highest and lowest overall accuracy respectively (Table 2 and 3). The overall classification accuracy based on the WV-2 eight bands was lower than the WV-2s strategically positioned bands while the overall accuracy based on WV-2s traditional bands (blue, green, red and NIR) was higher than the accuracy achieved using SPOT 5 image (Table 2 and 3). A summary of the fern accuracies for the four image categories are reported in Table 2 while the confusion matrices for the major land cover-types in the study area reported in Table $3 \mathrm{a}$ and $\mathrm{b}$.

Table 2: Summary results of the maximum likelihood classification showing only the bracken class and its accuracies (OA-Overall Accuracy, UA-User's Accuracy, PUProducers's Accuracy).

\begin{tabular}{lccc}
\hline & \multicolumn{3}{c}{ Bracken class (\%) } \\
& OA & UA & PA \\
\hline WV-2 8 bands & 73.77 & 75.65 & 63 \\
WV-2 traditional bands & 70.27 & 62.14 & 66.67 \\
WV-2 additional bands & 79.14 & 97.62 & 91.11 \\
SPOT 5 & 66.15 & 58.33 & 58.97 \\
\hline
\end{tabular}


Table 3: The confusion matrices from the maximum likelihood classification of the strategically positioned bands WV-2 image (A) and SPOT 5 image (B) - (UA-User's Accuracy, PU- Producers's Accuracy).

A

\begin{tabular}{lcccccccc}
\hline & Unclassified & Bracken fern & Grassland & Forest & Settlement & Water body & Totals & UA \\
\hline Unclassified & 0 & 0 & 0 & 0 & 0 & 0 & 0 & - \\
Bracken fern & 0 & 41 & 0 & 0 & 1 & 0 & 42 & $\mathbf{9 7 . 6 2 \%}$ \\
Grassland & 0 & 3 & 42 & 4 & 3 & 0 & 52 & $\mathbf{8 0 . 7 7 \%}$ \\
Forest & 0 & 1 & 2 & 38 & 2 & 0 & 43 & $\mathbf{8 8 . 3 7 \%}$ \\
Settlement & 0 & 0 & 6 & 17 & 20 & 0 & 43 & $\mathbf{4 6 . 5 1 \%}$ \\
Water body & 0 & 0 & 0 & 0 & 0 & 7 & 7 & $\mathbf{1 0 0 \%}$ \\
Totals & 0 & 45 & 50 & 59 & 26 & 7 & 187 \\
PA & - & $\mathbf{9 1 . 1 1 \%}$ & $\mathbf{8 4 . 0 0 \%}$ & $\mathbf{6 4 . 4 1 \%}$ & $\mathbf{7 7 \%}$ & $\mathbf{1 0 0 \%}$ & \\
Overall accuracy & $\mathbf{7 9 . 1 4 \%}$ & & & & & & &
\end{tabular}

B

\begin{tabular}{lcccccccc}
\hline & Unclassified & Bracken fern & Grassland & Forest & Settlement & Water body & Totals & UA \\
\hline Unclassified & 0 & 0 & 0 & 0 & 0 & 0 & 0 \\
Bracken fern & 0 & 23 & 25 & 4 & 0 & 0 & 52 & $\mathbf{5 8 . 3 3 \%}$ \\
Grassland & 0 & 5 & 25 & 3 & 9 & 0 & 42 & $\mathbf{5 9 . 5 2 \%}$ \\
Forest & 0 & 7 & 0 & 35 & 0 & 0 & 42 & $\mathbf{8 3 . 3 3 \%}$ \\
Settlement & 0 & 4 & 7 & 1 & 32 & 0 & 44 & $\mathbf{7 2 . 7 3 \%}$ \\
Water body & 0 & 0 & 0 & 0 & 0 & 7 & $\mathbf{1 0 0 \%}$ \\
Totals & 0 & 39 & 57 & 43 & 41 & 7 & 187 \\
PA & - & $58.97 \%$ & $43.85 \%$ & $81.40 \%$ & $78.05 \%$ & & \\
Overall accuracy & $\mathbf{6 6 . 1 5} \%$ & & & & & & \\
\hline
\end{tabular}


Visual inspection of the classified imagery (Figure 2) in concert with field data showed better classification accuracy using additional bands image, with smallest fern patches correctly identified in grass dominated areas (Figure 3C). Classifications based on WV-2s eight bands and traditional bands, Figure $2 \mathrm{a}$ and $\mathrm{b}$ respectively and the SPOT 5 image (Figure $2 \mathrm{~d}$ ) were less effective in delineating areas covered by the fern.

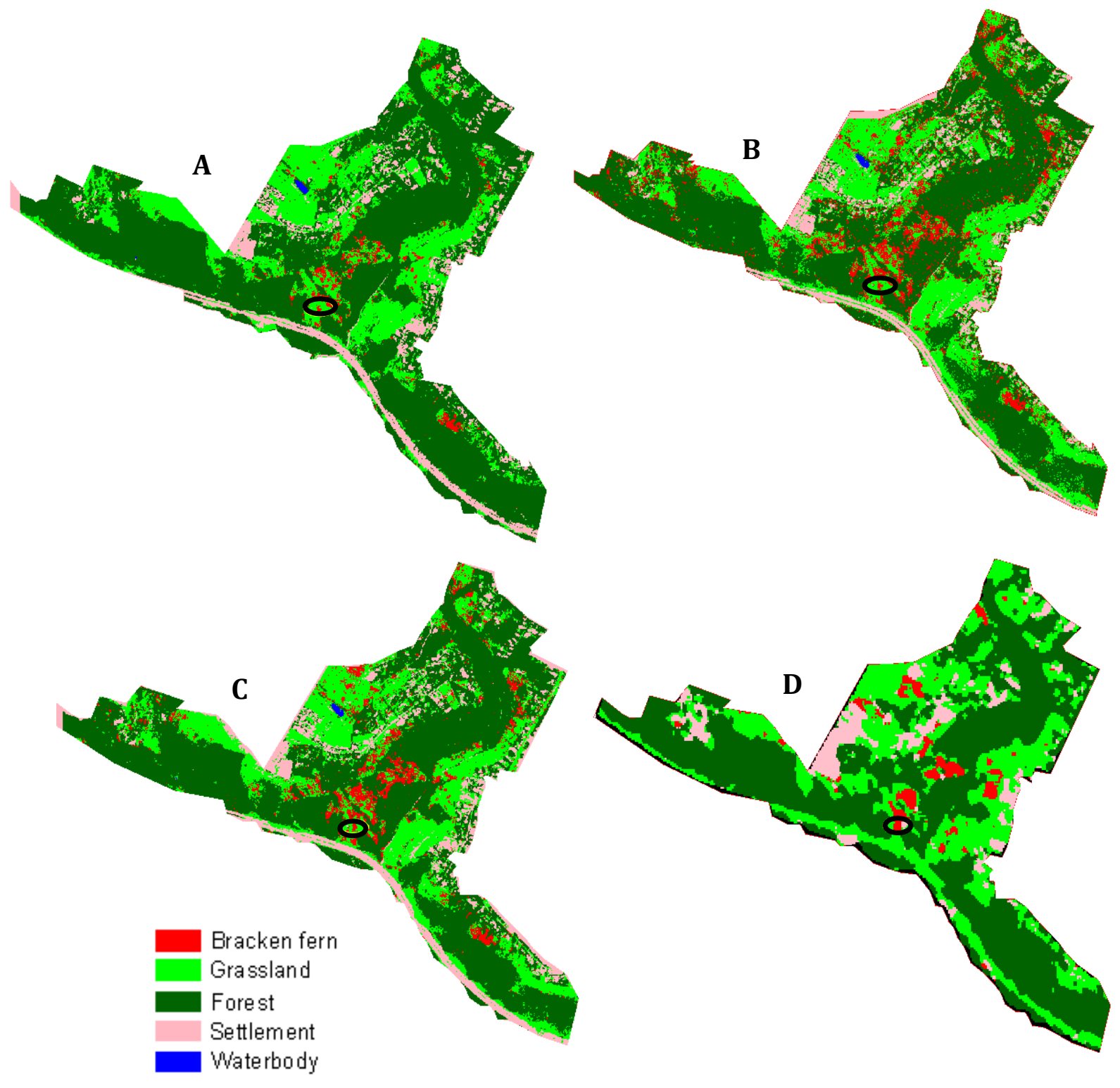

Figure 2: Maximum likelihood classification on (A) eight band WV-2 image, (B) traditional bands image, (C) additional bands image, (D) and SPOT 5 images. 

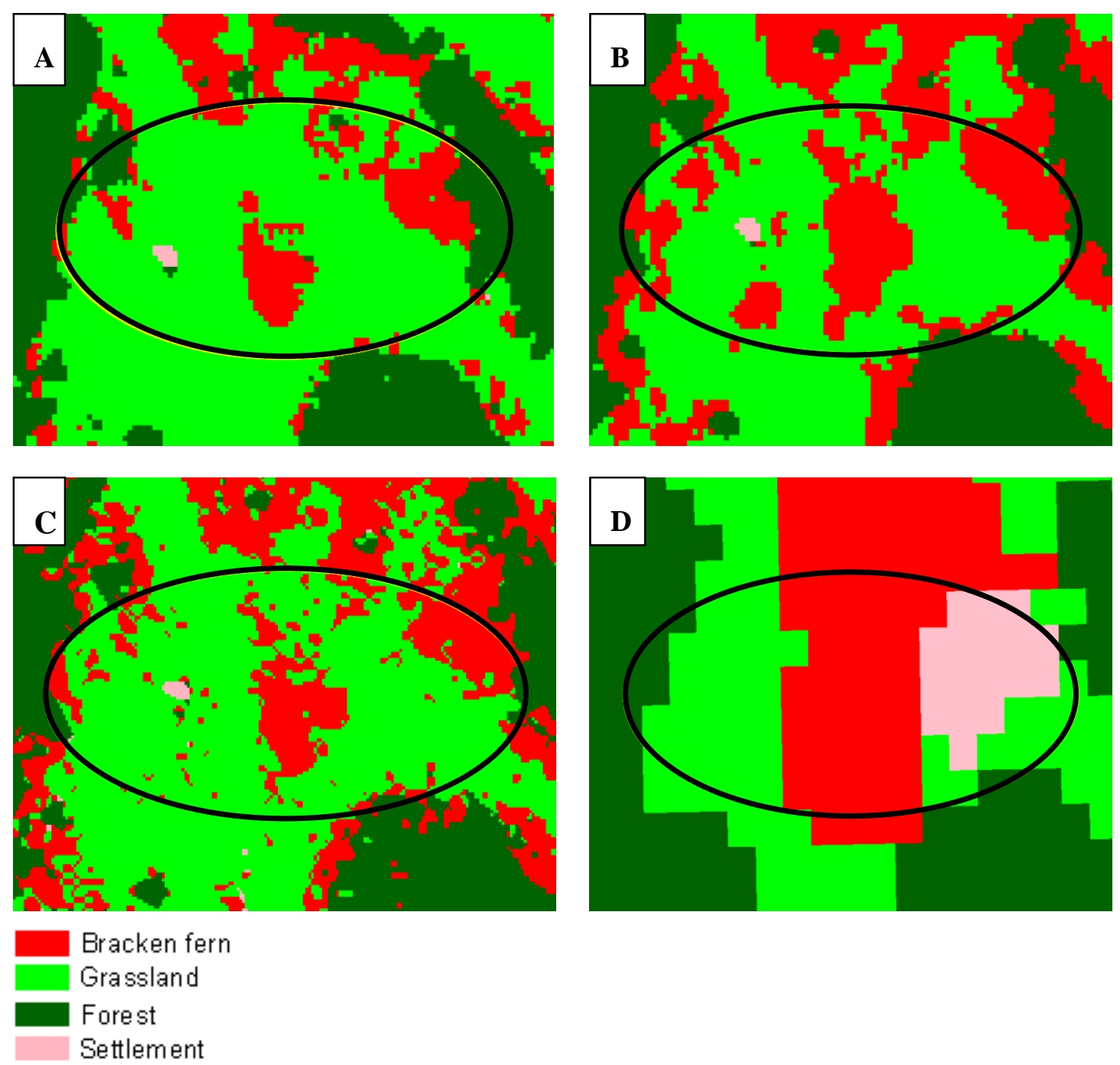

Figure 3: Insert of classification results (from Figure 2) on (A) eight band WV-2 image, (B) traditional bands image, (C) additional bands image, (D) and SPOT 5 image.

\section{Discussion}

This study explored the potential of new generation WV-2 sensor in mapping the fern. The position and the number of bands were assessed and compared to the four bands that characterise the SPOT 5 image. Results revealed that WV-2 additional bands (coastal blue, yellow, red-edge and NIR2) can improve the mapping accuracy. A number of studies (Chen 2010; Ozdemira and Karnielib 2011; Cho et al. 2012) note the potential of WV-2 additional bands in vegetation mapping. Using pixel-based approach, Chen (2010) demonstrated that the four additional bands were most suitable for differentiating tree species while Cho et al. (2012) identified WV-2s yellow band as the most influential in vegetation mapping. Ozdemira and Karnielib (2011) used WV-2s image texture to predict forest structure parameters and identified the WV-2s additional bands (yellow, red-edge and NIR2)as most suitable for predicting forest structure. Other studies (Dlamini 2010; Omar 2010) note the value of WV- 
$2 \mathrm{~s}$ coastal blue and red-edge portions in distinguishing vegetation species. The absorption of chlorophyll in the coastal blue band facilitates discrimination based on leaf chlorophyll content while extended NIR (1 and 2) broadens the spectrum for vegetation analysis.

Results in this study indicate suitability of the WV-2s improved spectral resolution in vegetation mapping in corroboration with studies reported by eg Mehner et al. (2004) and Holland and Aplin (2013). In comparison to other band combinations (see table 2), the strategically positioned bands have been known to be more sensitive to different levels of chlorophyll, foliage mass and leaf area index, and therefore suitable for discriminating different vegetation types (Daughtry and Walthall 1998; Cochrane 2000; Schmidt and Skidmore 2003). Consequently, these bands are valuable in discriminating the fern from other vegetation types.

The perfomance of all the WV-2s band combinations (see table 2) were superior to SPOT 5 image in discriminating the fern. This can be attributed to the lower spatial and spectral resolution that characterise the SPOT 5 image. Commonly, reliable classification based on imagery characetrised by lower spatial and spectral resolutions is impeded by the mixed pixel problem. As seen in this study (Figure 2 and 4), SPOT 5 imagery may be unsuitable for discriminating the fern from heterogeneous landscapes due to spectral confusion and mixed pixel problem.

Results in this study show the suitability of the additional and strategically positioned bands in WV2 imagery for mapping the fern. Areas around Giba Gorge are generally characterised by mild subtropical conditions during the year. In this regard, most of the months are ideal for acquiring imagery for mapping the fern. Since no site site specific fern's spectral uniqueness has ever been reported, use of similar data sets in diverse landscapes can be expected to produce similar results. However, typically, the fern is vulnerable to extreme winter conditions, causing a dieback. Consequently, in areas characterised by late winter frost conditions, image acquisition for mapping should be captured during the winter onset as the fern's folier response to extreme winter conditions may impede reliabled delineation.

\section{Conclusions}

This study explored the potential of WV-2 image data in mapping the fern. The position and the number of spectral bands were assessed and compared to the commonly used multispectral image (SPOT-5). The results showed that the additional bands in WV-2 are valuable in discriminating the fern from other vegetation types. The added spectral dimensions 
in this image improve classification accuracy. It is concluded that the discrimination among the physical characteristic of targets mapped is enhanced by the unique combination of fine spatial and spectral resolutions in this imagery. Whereas the distribution of the fern was also observed in other band categories, their classification accuracies were relatively lower than those from the additional bands. Although the study was restricted to one study site, it is suggested that the approach be tested at other sites to verify the use of WV-2 imagery in mapping the fern.

\section{Acknowledgement}

The authors would like to acknowledge the UKZN-eThekwini Municipality Sandstone Sourveld Research Programme team members for the valuable input and eThekwini Municipality's Environmental Planning and Climate Protection Department for the financial support.

\section{References}

Abd El-Kawy, O, Rød, J, Ismail, H \& Suliman, A 2011, 'Land use and land cover change detection in the western Nile delta of Egypt using remote sensing data', Applied Geography, vol. 31 no. 2, pp. 483-494.

Atkinson, PM \& Lewis, P, 2000, 'Geostatistical classification for remote sensing: An introduction', Computers and Geosciences, vol. 26 no 4, pp. 361-371.

Birnie, R \& Miller, D 1986, 'The bracken problem in Scotland: a new assessment using remotely sensed data', in RT Smith, and JA Taylor (eds.), Bracken: ecology, land use and control technology, Parthenon Press, New York.

Chen, Q 2010, 'Comparison of Worldview-2 and IKONOS-2 imagery for identifying tree species in the habitat of an endangered bird species in Hawaii', DigitalGlobe ${ }^{\circledR} 8$-Bands Research Challenge, 23.

Cho, MA, Mathieu, R, Asner, GP, Naidoo, L, van Aardt, J, Ramoelo, A, Debba, P, Wessels, K, Main, R, Smit, IPJ \& Erasmus, B 2012, 'Mapping tree species composition in South African savannas using an integrated airborne spectral and LiDAR system', Remote Sensing of Environment, vol. 125, pp. 214-226.

Cho, MA, Debba, P, Mutanga, O, Dudeni-Tlhone, N, Magadla, T and Khuluse, SA 2012, 'Potential utility of the spectral red-edge region of SumbandilaSat imagery for assessing indigenous forest structure and health', International journal of applied earth observation and Geoinformation, vol. 16, pp. 85-93.

Cochrane, MA 2000, 'Using vegetation reflectance variability for species level classification of hyperspectral data', Internation Journal of Remote Sensing, vol. 21, pp. 2075-2087. 
Congalton, RG 1991, 'A review of assessing the accuracy of classification of remotely sensed data', Remote Sensing of Environment, vol. 37, pp. 35-46.

Cohen, WB \& Spies, TA 1992, 'Estimating structural attributes of Douglas-fir/western hemlock forest stands from Landsat and SPOT imagery', Remote Sensing of Environment, vol. 41, no. 1 pp. 1-17.

Dalponte, M, Bruzzone, L, Vescovo, L \& Gianelle, D 2009, 'The role of spectral resolution and classifier complexity in the analysis of hyperspectral images of forest areas', Remote Sensing of Environment, vol.113 no. 11, pp. 2345-55.

Daughtry, CST \& Walthall, CL 1998, 'Spectral discrimination of Cannabis sativa L . leaves and canopies. Remote Sensing of Environment', vol. 201, pp. 192-201.

Dlamini, WM 2010, 'Multispectral detection of invasive alien plants from very high resolution 8-band satellite imagery using probabilistic graphical models', DigitalGlobe ${ }^{\circledR}$ 8-Bands Research Challenge, pp. 1-17.

EThekwini Municipality 2012/2013. eThekwini Municipality Draft Integrated Development Plan. Durban.

Foody, GM 2002, 'Status of land cover classification accuracy assessment', Remote Sensing of Environment, vol. 80, pp. 185-201.

Fuller, RM, Groom, GB \& Jones, AR 1994, 'The land cover map of Great Britain: an automated classification of Landsat Thematic Mapper data', Photogrammetric Engineering \& Remote Sensing, vol. 60, no. 5, pp. 553-562.

French, AN, Schmugge, TJ, Ritchie, JC, Hsu, A, Jacob F \& Ogawa K 2008, 'Detecting land cover change at the Jornada Experimental Range, New Mexico with ASTER emissivities', Remote Sensing of Environment, vol. 112, no. 4, pp. 1730-48.

Giri, C, Defourny, P \& Shrestha S 2003, 'Land cover characterization and mapping of continental Southeast Asia using multi-resolution satellite sensor data', International Journal of Remote Sensing, vol. 24, no. 21, pp. 4181-4196.

Holland, J \& Aplin, P 2013, 'Super-resolution image analysis as a means of monitoring bracken (Pteridium aquilinum) distributions', ISPRS Journal of Photogrammetry and Remote Sensing, vol. 75, pp. 48-63.

Hudak, A T \& Wessman, CA 2001, 'Textural analysis of high resolution imagery to quantify bush encroachment in Madikwe Game Reserve, South Africa, 1955-1996', International Journal of Remote Sensing, vol. 22, no. 14, pp. 2731-2740.

Jensen JR, 2005, Introductory Digital Image Processing: A Remote Sensing Perspective. $3^{\text {rd }}$ edition, Prentice Hall, Upper Saddle River, New Jersey.

Kanellopoulos, IA, Varfis GG, Wilkinson, K \& Megier, J. 1992, 'Land-cover discrimination in SPOT HRV imagery using an artificial neural network-a 20-class experiment', International Journal of Remote Sensing, vol. 13, no. 5, pp. 917-24.

Kavzoglu, T, Colkesen, I 2009, 'A kernel functions analysis for support vector machines for land 
cover classification', International Journal of Applied Earth Observation and Geoinformation, vol. 11, pp. 352-359.

Lindenmayer, D, Blair, D \& McBurney, L 2010, Forest Phoenix: How a Great Forest Recovers After Wildfire. CSIRO, Publishing, Victoria.

Liu, C, Samolyuk, G, Lee, Y, Ni, N, Kondo, T, Santander-Syro, A, Bud'ko, S, McChesney, J, Rotenberg, E \& Valla, T 2008, 'K-Doping Dependence of the Fermi Surface of the Iron-Arsenic $\mathrm{Ba}_{-}\{1-\mathrm{x}\} \mathrm{K}_{-}\{\mathrm{x}\} \mathrm{Fe}_{-}\{2\} \mathrm{As}_{-}\{2\}$ Superconductor Using Angle-Resolved Photoemission Spectroscopy', Physical Review Letters, vol. 101, no. 17, pp. 177005.

Lu, D, Mausel, P, Brondízio, E, Moran, E, 2004, 'Change detection techniques', International Journal of Remote Sensing, vol. 25, pp. 2365-2401.

Marrs, RH, Le Duc, MG, Mitchell, R, Goddard, D, Paterson, S \& Pakeman, RJ 2000, 'The ecology of bracken: its role in succession and implications for control', Annals of Botany, vol.85, pp. 3-15.

Mehner, H, Cutler, M, Fairbairn, D \& Thompson, G 2004, 'Remote sensing of upland vegetation: the potential of high spatial resolution satellite sensors', Global Ecology and Biogeography, vol. 13, no. 4, pp. 359-369.

Miller, D, Morrice, J \& Whitworth, P 1989, The bracken problem in Scotland, The Macaulay Land Use Research Institute, Aberdeen.

Miller, D, Morrice, J \& Whitworth, P 1990, 'Bracken distribution and spread in upland Scotland: an assessment using digital mapping techniques', in J Thomson, and R Smith, (eds.), Bracken biology and management. Australian Institute of Agricultural Science, Occassional Publication, Sydney.

Msibi, M 2011, 'Local Action for Biodiversity: Bush encroachment Ecofiles Sheet 3,' EThekwiniMunicipality, Durban.

Mucina, L \& Rutherford, MC 2006, The Vegetation Map of South Africa, Lesotho and Swaziland, SANBI, Pretoria.

Mutanga, O, Adam, E. \& Cho M 2012, 'High density biomass estimation for wetland vegetation using WorldView-2 imagery and random forest regression algorithm', International Journal of Applied Earth Observation and Geoinformation, vol. 18, pp. 399-406.

O'Connor, TG 2005, 'Influence of land use on plant community composition and diversity in Highland Sourveld grassland in the southern Drakensberg, South Africa', Journal of Applied Ecology, vol. 42, pp. 975-988.

Omar, H 2010, 'Commercial timber tree species identification using multispectral Worldview2 data', DigitalGlobe ${ }^{\circledR}$ 8-Bands Research Challenge, vol. 2-3, pp. 68-87.

Ozdemira, I \& Karnielib, A 2011, 'Predicting forest structural parameters using the image texture derived from WorldView-2 multispectral imagery in a dryland forest, Israel', International Journal of Applied Earth Observation and Geoinformation, vol. 13, pp. 701-710.

Pakeman, RJ, Marrs, RH, Howard, DC, Barr, CJ \& Fuller, RM 1996, 'The bracken problem in Great Britain: Its present extent and future changes', Applied Geography, vol. 16, no. 1, pp. 65-86. 
Petropoulos, G, Kalaitzidis, C \& Vadrevu. K. 2012, 'Support vector machines and object-based classification for obtaining land-use/cover cartography from Hyperion hyperspectral imagery', Computers \& Geosciences, vol. 41, pp. 99-107.

Petropoulos, G. Arvanitis, K \& Sigrimis, N 2012, 'Hyperion hyperspectral imagery analysis combined with machine learning classifiers for land use/cover mapping', Expert systems with Applications, vol. 39, no. 3, pp. 3800-3809.

Pignatti, S, Cavalli, R, Cuomo, V, Fusilli, L, Pascucci, S, Poscolieri, M \& Santini, F 2009, 'Evaluating Hyperion capability for land cover mapping in a fragmented ecosystem: Pollino National Park, Italy', Remote Sensing of Environment, vol. 113, no. 3, pp. 622-34.

Roos, K, Rollenbeck, R, Peters, T, Bendix, J \& Beck, E 2010, 'Growth of tropical bracken (Pteridium arachnoideum): response to weather variations and burning', Invasive Plant Science and Management, vol. 3, pp. 402-411.

Schmidt, KS \& Skidmore, AK 2003, 'Spectral discrimination of vegetation types in a coastal wetland', Remote Sensing of Environment, vol. 85, no. 92-108.

Schneider, L \& Fernando, D 2010, 'An untidy cover: invasion of bracken fern in the shifting cultivation systems of southern Yucatán, Mexico', Biotropica, vol. 42, no. 41-48.

Stefanov, WL \& Netzband M. 2005, 'Assessment of ASTER land cover and MODIS NDVI data at multiple scales for ecological characterization of an arid urban center', Remote Sensing of Environment, vol. 99, no. 1, pp. 31-43.

Tong, C, Leduc, M, Ghorbani, J \& Marrs, R 2006, 'Linking restoration to the wider landscape: A study of a bracken control experiment within a upland moorland landscape mosaic in the Peak District, UK', Landscape and Urban Planning, vol. 78, no. 115-134.

Vogelmann, JE, TL Sohl, PV Campbell, \& DM Shaw. 1998, 'Regional land cover characterization using Landsat Thematic Mapper data and ancillary data sources,' Environmental Monitoring and Assessment, vol. 51, no. 1, pp. 415-28.

Wigley, BJ, Bond, WJ \& Hoffman, MT 2009, 'Bush encroachment under three contrasting land-use practices in a mesic South African savanna', African Journal of Ecology, vol. 47, pp. 62-70.

Wu, W and Shao, G 2002, 'Optimal Combinations of Data Classifiers', Remote Sensing, vol. 28, no. 4, pp. 601-609.

Wulder, MA, White, JC, Goward, SN, Masek, JG, Irons, JR, Herold, M., Cohen, WB, Loveland, TR \& Woodcock, CE 2008, 'Landsat continuity: Issues and opportunities for land cover monitoring', Remote Sensing of Environment, vol.112, vol. 3, pp. 955-69.

Xie, Y, Sha, Z \& Yu, M 2008, 'Remote sensing imagery in vegetation mapping : a review', Journal of Plant Ecology, vol.1, no. 1, pp. 9-23. 